\title{
Early Loading of Variobase Abutment Restored Hydrophilic Implants in Single Edentulous Posterior Regions
}

CLINICAL

Pan Yu *Sun Haipeng Liu Wenfang Huang Shengxing

Stomatology Center of Shenzhen People's Hospital, Second Medical School of Ji Nan University, Shenzhen ,China

*shplysz@126.com

\section{Background}

Improved surface chemistry can efficiently optimized osseointegration of dental implants, aiming in shorten healing period before loading. The chemically active, hydrophilic surface promotes the initial healing reaction, allowing for direct cell interaction at the initial stage of the osseointegration process. Bone formation is immediately initiated resulting in earlier secondary stability, therefore reducing the critical dip. Enhance of osseointegration implies greater security and higher predictability in early treatment.

\section{Aim}

To evaluate early clinical outcome of Variobase abutment restored hydrophilic implants in single posterior edentulous cases.

\section{Methods and Materials}

Thirty-eight single edentulous posterior sites were chosen to restored with Strauman SLAactive implants in 38 patients. Implant stability quotient (ISQ) was measured six weeks after surgery and permanent restorations were established eight weeks after insertion, with integrated abutment crowns (IACs) manufactured from Variobase abutments. Regularly follow-up was made, a periapical X-ray was taken at each follow-up time.

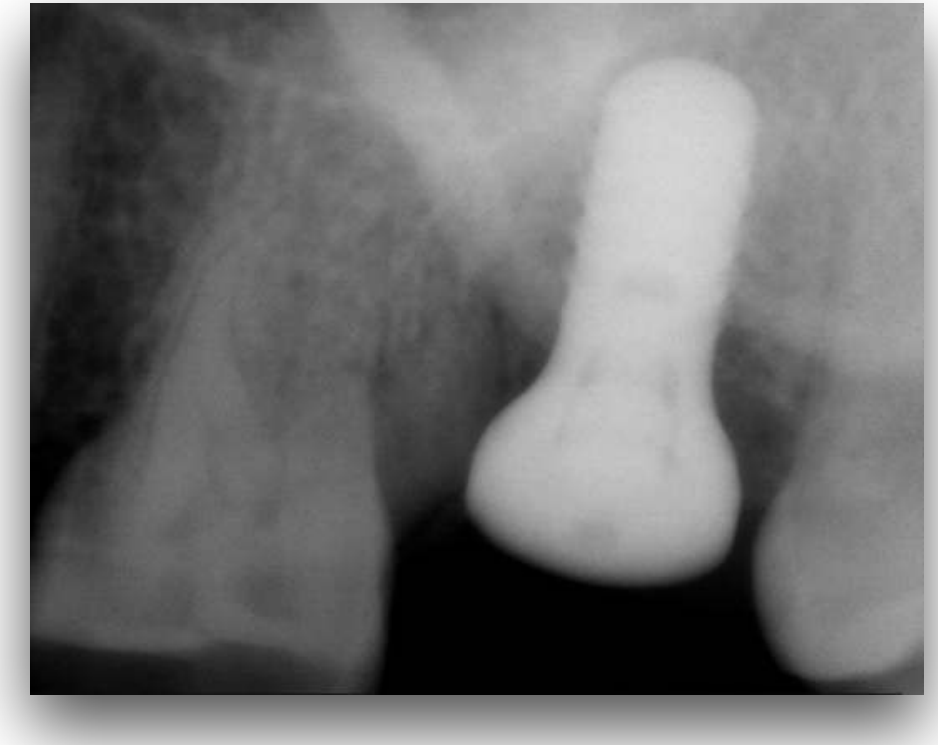

Fig.1 x-ray after insertion

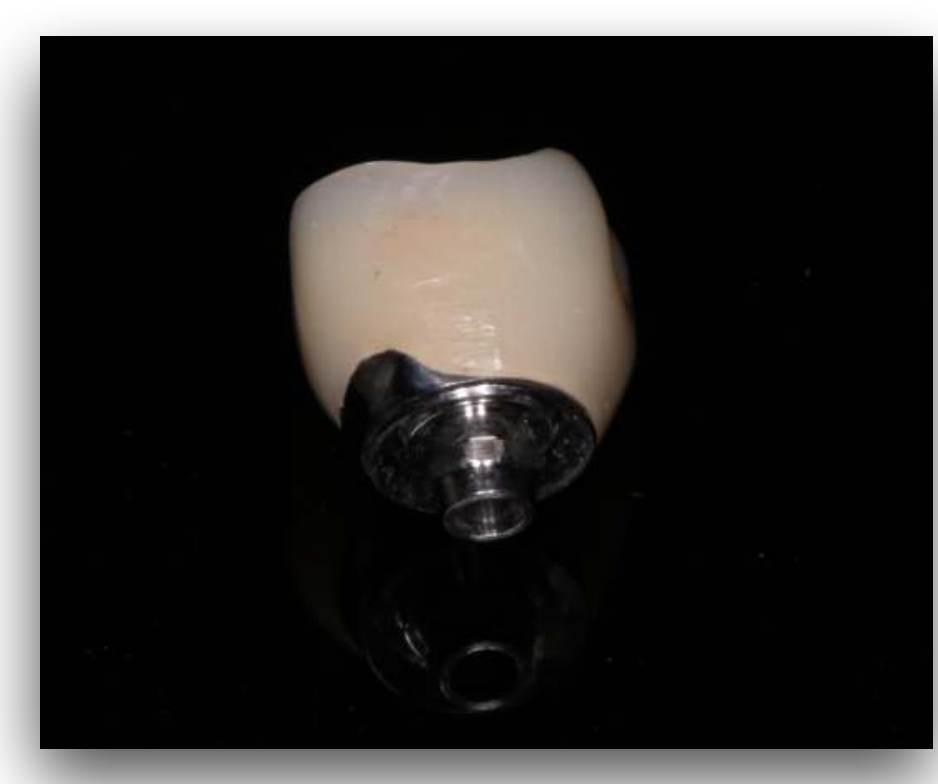

Fig.3 IACs manufactured from Variobase

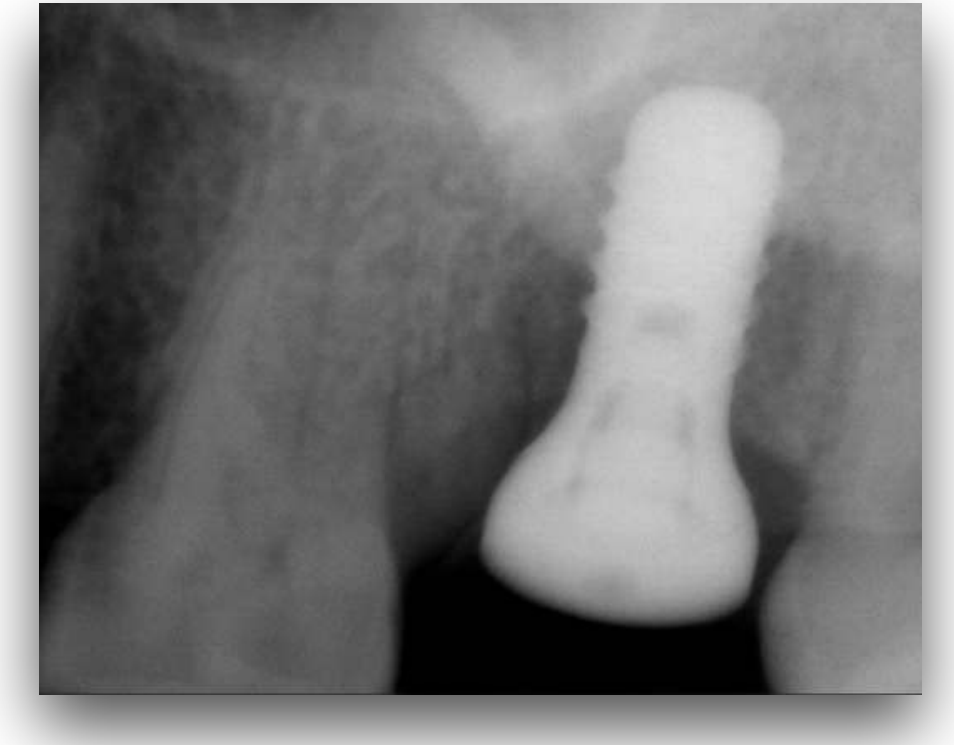

Fig. $2 \mathrm{x}$-ray after 6 weeks

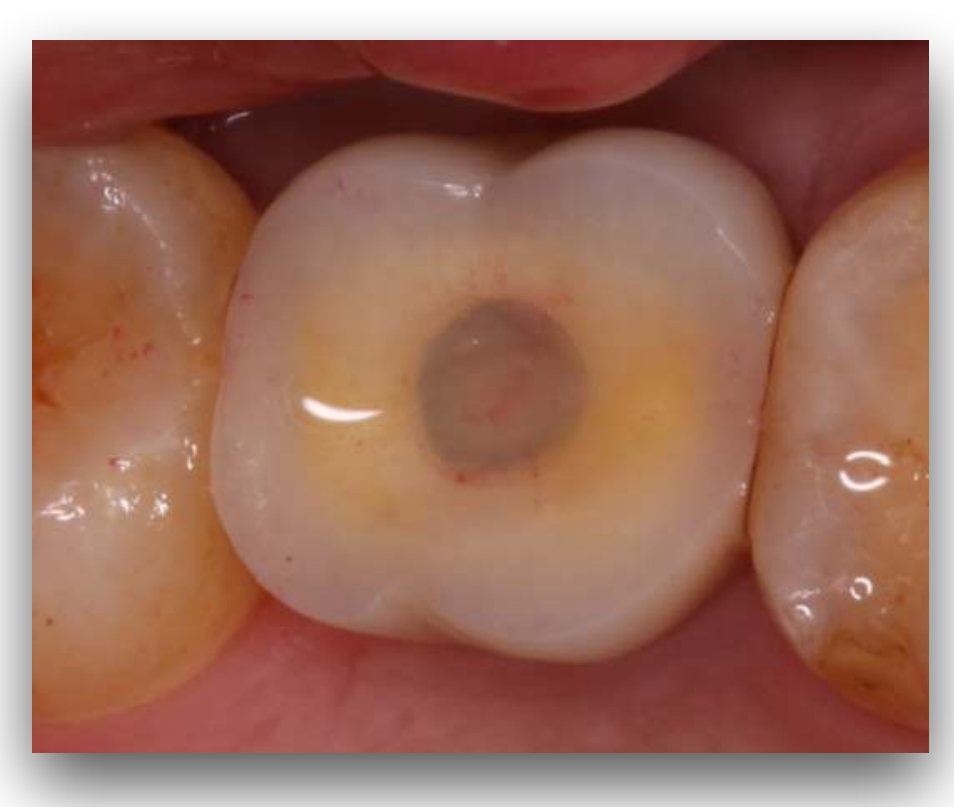

Fig.4 Final restoration

\section{Results}

All thirty-eight SLAactive implants achieved predictable stability in six weeks. ISQ in vertical direction is $80.8 \pm 3.9$, and $79.7 \pm 4.1$ in horizontal direction. X-ray showed no bone malformation or absorption around implants and no excess cement at the edge of crown, indicating satisfying bone integration. The restorations' success rate after eight weeks load is $100 \%$, no implants failed after one year of follow-up.

$\begin{array}{cccc} & \text { Table-1 } & \text { General info } & \\ \text { Total } & 35 & \text { Implant } & 38 \\ \text { (person) } & & \text { Maxilla } & 18 \\ \text { Male } & 20 & \text { Mandible } & 20 \\ \text { Female } & 18 & & \\ \begin{array}{c}\text { average age } \\ \text { (yrs) }\end{array} & 38 & & \end{array}$

$\begin{array}{ccc}\text { table-2 } & \text { ISQ examination after } 6 \text { weeks } \\ & \text { Buccle } & \text { Lingual } \\ \text { Max } & 86 & 86 \\ \text { Min } & 67 & 67 \\ \text { Mean } & 79.7 & 80.8 \\ \text { Sd } & 4.1 & 3.9\end{array}$

\section{Conclusions}

With our limitation, permanent IACs restoration manufactured from Variobase abutment is safe to restore hydrophilic implant at six weeks after insertion, long-term effect remains to be observed. Variobase abutment is a strong foundation for treatment flexibility and allows technicians to remove excess cement and visually inspect the cement margin. Delivering a one-piece restoration may save chair time.

\section{References}

[1] Mokhtarpour H, Ashtiani RE, Mahshid M, Tabatabaian F, Alikhasi M.Effect of screw access hole preparation on fracture load of
implant-supported zirconia-based crowns: an in vitro study. Dent Res Dent Clin Dent Prospect 2016;10:181-8. [2] Al-Omari WM, Shadid R, Abu-Naba'a L, El Masoud B. Porcelain fracture resistance of screw-retained, cement-retained, and
screw-cement-retained implant-supported metal ceramic posterior crowns. J Prosthodont 2010;19:263-73. [3] Urdaneta RA, Marincola M, Weed M, Chuang SK. A screwless and cementless technique for the restoration of single-tooth
implants: a retrospective cohort study. J Prosthodont 2008; 17:562-71. [4] Hussien AN, Rayyan MM, Sayed NM, Segaan $L G$, Goodacre CJ, Kattadiyi MT. Effect of screw-access channels on the fracture
resistance of 3 types of ceramic implant-supported crowns. J Prosthet Dent 2016;116:214-20. [5] Derafshi R, Farrin M, Taghva M, Heidary H, Atashkar B. The Effects of New Design of Access Hole on Porcelain Fracture
Resistance of Implant-Supported Crowns. J Dent Shiraz Univ Med Sci 2015;16:61-7. [6] Jung RE, Pjeturesson BE, Glauser R, Zembic A, Zwahlen M, Lang NP. A systematic review of the 5 year survival and complication
rates of implant supported single crowns. Clin Oral Implant Res 2008; 19:119-30. [7] Albosefi A, Finkelman M, Zandparsa R. An in vitro comparison of fracture load of zirconia custom abutments with internal
connection and different angulatitions and thickness: part I. J Prosthodont 2014; 23:296-301. [8] Kammermeier A, Rosentritt M, Behr M, Schneider-Feyrer S, Preis V. In vitro performance of one- and two-piece zirconia implant
systems for anterior application. D Dent 2016;53:94-101. 